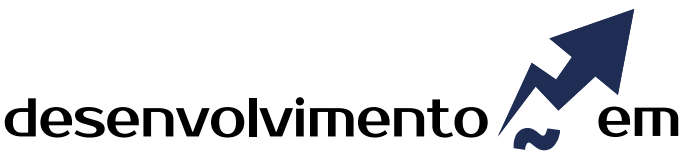 QUESTÂO
}

\section{Contribuição da Teoria da Dádiva para os Estudos Territoriais}

\author{
http://dx.doi.org/10.21527/2237-6453.2020.53.72-90
}

Recebido em: 20/5/2019

Aceito em: 30/7/2020

Anderson Luis do Espirito Santo, ${ }^{1}$ Douglas Josiel Voks ${ }^{2}$

\begin{abstract}
RESUMO
Marcel Mauss é o grande idealizador da teoria da dádiva, que permite, dentre outras viabilidades, analisar como a troca e o simbolismo possibilitam a socialização e a comunicação entre os atores. Neste artigo buscamos identificar sua contribuição por meio da teoria da dádiva para o desenvolvimento de novos estudos territoriais. Nosso objetivo aqui, portanto, é conferir, à luz dessa teoria, como ocorrem as relações de troca e a presença do simbolismo nas feiras livres na fronteira Brasil-Bolívia, mediante um trabalho qualitativo e sob um enfoque etnográfico. Paralelamente, discutimos a contribuição da Sociologia Econômica e da Nova Sociologia Econômica para os estudos urbanos, sustentáveis e regionais pelo aporte da corrente francófona do "dom". A partir de uma construção teórico-empírica aplicada a uma análise de caso, é possível afirmar que a teoria da dádiva permite reconhecer diversos fenômenos sociais presentes no território com ênfase no ator, e como isto é importante para o desenvolvimento da região. Permitiu, também, perceber a importância de se estudar os mercados sob o ângulo econômico, sociológico e histórico, ou seja, como construções sociais, pois, no caso das feiras, foram identificados alguns símbolos trocados, o que viabilizou criar um olhar para além do utilitarismo e compreender como ocorre a dinâmica de desenvolvimento do território e a existência e a manutenção das feiras.
\end{abstract}

Palavras-chave: Teoria da dádiva. Desenvolvimento. Estudos territoriais. Nova sociologia econômica.

\section{CONTRIBUTION OF THE GIFT THEORY TO TERRITORIAL STUDIES}

\begin{abstract}
Marcel Mauss is the great creator of the theory of gift, which allows, among other possibilities, to analyze how exchange and symbolism enable socialization and communication between actors. In this article, we seek to identify its contribution, through the gift theory, to the development of new territorial studies. Our objective here, therefore, is to check, in the light of this theory, how exchange relations and the presence of symbolism occur in open markets on the Brazil-Bolivia border, through qualitative work and under an ethnographic approach. At the same time, we discussed the contribution of Economic Sociology and New Economic Sociology to urban, sustainable and regional studies due to the contribution of the francophone current of "gift". From a theoretical-empirical construction applied to a case analysis, it is possible to state that the gift theory allows the recognition of several social phenomena present in the territory, with an emphasis on the actor, and how important this is for the development of the region. It also made it possible to perceive the importance of studying the markets from an economic, sociological, historical perspective, that is, as social constructions, since, in the case of fairs, some exchanged symbols were identified, which made it possible to create a look beyond utilitarianism and understand how the dynamics of territory development occurs and the existence and maintenance of fairs.
\end{abstract}

Keywords: Gift theory. Development. Territorial studies. New economic sociology.

\footnotetext{
${ }^{1}$ Mestre em Estudos Fronteiriços pela Universidade Federal de Mato Grosso do Sul (UFMS). Doutorando em Administração pela Universidade do Estado de Santa Catarina (Udesc). Professor da Universidade Federal de Mato Grosso do Sul (UFMS), Campus do Pantanal. http://lattes.cnpq.br/7394122912242974. https://orcid.org/0000-0001-6507-974X. anderson84luis@gmail.com

2 Doutor e mestre em História pela Universidade do Estado de Santa Catarina (Udesc). Professor da Universidade Federal de Mato Grosso do Sul (UFMS). Campus do Pantanal. http://lattes.cnpq.br/3967850733362541. https://orcid.org/0000-0002-7725-4389. douglas_voks@hotmail.com
} 
Desde a década de 80 do século 20 , quando do surgimento e consolidação do movimento teórico-empírico iniciado pela Nova Sociologia Econômica (NSE), pesquisadores de diversas partes do mundo voltaram a realizar investigações de fenômenos econômicos a partir da confluência entre a economia e a sociologia, intercambiando os processos políticos, culturais, econômicos, institucionais, simbólicos e sociais em suas análises. Tal consolidação refletiu-se em distintas abordagens referentes à NSE, das quais este estudo apresenta o Movimento Antiutilitarista nas Ciências Sociais (Mauss) surgido na França, e que se baliza a partir dos estudos de Marcel Mauss (1872-1950), especificamente os "Ensaios sobre a Dádiva".

A sociologia da dádiva de Mauss vem ganhando corpo nas ciências sociais, pois, partindo de uma visão antiutilitarista, ela permite identificar como ocorrem a circulação de bens (materiais e simbólicos) e a reciprocidade nas sociedades por meio do dom e do contradom - que cria, recria e fortalece os vínculos da sociedade mediante a (re)criação do laço social. Além de Mauss, as obras de Caillé e Godbout também formam referência para este trabalho, pois esses autores teorizam sobre a existência da teoria da dádiva na sociedade moderna. Esta pesquisa, em confluência com esses autores, mostra como a teoria se faz presente na atualidade, pois, no momento da observação de campo, foi possível perceber as interações entre as relações econômicas, sociais e culturais, elementos da simbologia da dádiva, fundamental para compreender o território.

Sem embargo, a teoria de Mauss apresenta a dádiva muito mais que uma simples imagem ou algo que se remeta à fé. Trata-se de um sistema paradoxal que permite analisar como a troca possibilita diferentes socializações e a comunicação entre as diversas pessoas. Tendo por base essa afirmativa, é propósito deste artigo elaborar uma concepção teórico-empírica para o campo de estudos territoriais: analisar, à luz da teoria da dádiva, como ocorrem as relações de troca e a presença do simbolismo nas feiras livres da fronteira Brasil-Bolívia. Paralelamente, discutimos a contribuição da Sociologia Econômica e a consolidação da NSE nos estudos do desenvolvimento territorial, sustentáveis e regionais a partir do aporte da corrente francófona do Dom, ${ }^{3}$ possibilitando, assim, compreender o território a partir das ações e práticas dos indivíduos (análise micro); neste caso, as que emergiram nas feiras livres de Corumbá, na fronteira Brasil-Bolívia. Nessa opção buscamos entender: qual a contribuição da teoria da dádiva para o desenvolvimento de novos estudos territoriais.

Tais estudos, dentro do processo de desenvolvimento, ganham ímpeto no início dos anos 1980, sob influência da literatura neo-marshalliana, que buscava identificar a composição e os diferentes laços entre os atores, o que culminou com a formação de sistemas produtivos localizados (ABRAMOVAY, 2010). Já nas últimas décadas, novas discussões, em âmbito mundial, como a inscrição territorial e ecologicamente sustentável da natureza, levaram a incorporar a preocupação com a biodiversidade, colocando-se como alternativas no sentido de promover a resiliência e novos estilos e dinâmicas mais sustentáveis e inclusivos como componentes de estratégia de desenvolvimento (SACHS, 2009; LÉVESQUE, 2010).

\footnotetext{
${ }^{3}$ Esse termo pode variar de acordo com a tradução. "Le Don", ou, no inglês, "the gift", e pode ser encontrado como "a graça", "o dom" "a dádiva". Aqui adotaremos as duas últimas alternativas.
} 
Neste sentido, emerge a importância do trabalho de campo para os estudos territoriais, pois o território é um objeto de múltiplas representações, em que os atores, a partir de sua ação, experiência e visão de mundo, atribuem significados a determinados eventos. Além do viés econômico, as representações sociais, religiosas, políticas, culturais e ambientais vão desenhar e demonstrar a construção social e fornecer um melhor entendimento sobre as relações de mercado (SWEDBERG, 2005). Isto justifica a importância de se acompanhar os atores.

Este trabalho foi realizado em base empírica nas feiras livres da cidade de Corumbá (Mato Grosso do Sul, Brasil). Trata-se de uma zona fronteiriça (Brasil-Bolívia) marcada por complementaridades e diversos tipos de relações de troca, conflitos, articulações e comunicação. A presença do feirante boliviano é notória nessas feiras, o que a caracteriza como um verdadeiro ponto de encontro da população fronteiriça (brasileiros e bolivianos), que, além de adquirir seus produtos, ainda experimenta um caudaloso sabor cultural em sete feiras espalhadas pela cidade. Estudar as feiras livres em zonas fronteiriças é um desafio em razão da complexidade da vida nas cidades situadas nessas zonas. O conceito de fronteira é constantemente submetido a uma profunda discussão e ressignificação. Aqui ela é interpretada a partir da visão de Benedetti (2018), que a considera um espaço de vida. Para o autor, é uma "zona fronteiriça" no sentido de uma faixa que concentra habitantes, moradias, lazer, educação, sociabilidades diversas, atividades econômicas, etc.

Não se trata, pois, de apenas criar um tema, um foco ou um único olhar sobre a fronteira. É preciso aprofundar os estudos e incorporar novas possibilidades (teoria da dádiva) que permitam identificar a multiplicidade de fatores e identidades existentes, além de suas diferenças e conflitos que diretamente incidem nas dinâmicas de desenvolvimento da região.

A partir desta introdução, este artigo desenvolverá três partes teóricas que apresentam o debate entre a sociologia econômica, a NSE, a "dádiva" e a demonstração de como tudo isso pode ser frutífero para os estudos territoriais por intermédio de análises empíricas. Seguem-se a metodologia de pesquisa e os resultados divididos em duas partes: a primeira traz a trajetória histórica das feiras, explicando a feição que hoje apresentam; a segunda analisa a presença do simbolismo e a relação de trocas. Concluiremos com as considerações finais e as referências bibliográficas adotadas neste trabalho.

\section{DA SOCIOLOGIA ECONÔMICA À NOVA SOCIOLOGIA ECONÔMICA: UMA BREVE INTRODUÇÃO}

A primeira menção ao termo "Sociologia Econômica" apareceu inicialmente nos trabalhos do economista William Stanley Jevons no Reino Unido em 1879. No final do século 19, entretanto, é que a expressão foi retomada e disseminada pelos grandes sociólogos clássicos, nomeadamente Émile Durkheim, Max Weber, Georg Simmel e Karl Marx, quando se buscava compreender as ações econômicas sob as variáveis sociológicas, como crença, influência, coerção, dentre outros fenômenos sociais que incitam o comportamento econômico. A sociologia econômica, para Swedberg (2005, p. 233), é "o conjunto de teorias que se esforçam por explicar os fenômenos econômicos a partir de elementos sociológicos". Seu objetivo central é analisar como ocorrem a construção 
social das relações de mercado e as primícias da origem social dos fenômenos econômicos. A disciplina propunha trazer novos olhares - respostas - para questionamentos não resolvidos pela teoria econômica, e não substituí-la.

De acordo com Lévesque (2007), apesar de grande expressão desde a década de 20 até meados da década de 70 , ambas do século 20, a sociologia econômica passou por uma grande recessão e seu termo ficou negligenciado. Durante esse período deu-se aos estudos ênfase que, predominantemente, se dava às condições sociais das transformações econômicas, ou à disseminação do paradigma parsoniano, conhecido como economia e sociedade, áreas em que os estudos da sociologia foram se especializando cada vez mais - subdivididos em sociologia do trabalho, industrial, das organizações, do desenvolvimento, dentre outras, de tal modo que os sociólogos acabaram deixando para os economistas os objetos centrais da economia, tais como estudos de mercado, moeda e outros.

É preciso ressaltar que, apesar desse período de separação, alguns trabalhos ainda consideravam o viés preconizado pela sociologia econômica. Em 1944 surgiu a célebre obra de Karl Polanyi, denominada "A Grande Transformação: as origens da nossa época". Nela, o autor mostrou que a economia de mercado não possuía todas as atividades necessárias à reprodução social e à sobrevivência da vida humana. Polanyi (1980) defendia que o mercado, entre diversas formas de estrutura social, era uma forma de coordenar a luta e a sobrevivência da espécie; percepção esta que ia contra a visão dominante da época, firmada na racionalização econômica. Esta obra foi de grande valia e contribuiu para a consolidação da sociologia econômica, influenciando diversos autores, os quais, mais tarde, retomariam seus estudos e os de outros autores clássicos.

Nos anos 1980 a sociologia econômica "ressurge com intensidade, voltando seu interesse para as bases deixadas pelos seus precursores, ou seja, os estudos dos fenômenos econômicos à luz de uma abordagem sociológica" (SERVA; ANDION, 2007, p. 12). A partir dessa retomada criam-se as bases para a NSE, cujo mérito foi o de analisar sociologicamente o núcleo da ciência econômica, isto é, o mercado, considerado estrutura social. Muitos autores são de opinião que o termo NSE surge do estudo de Mark Granovetter, intitulado "Economic Action and Social Structure: the problem of embeddedness", de 1985 (SMELSER; SWEDBERG, 2005; STEINER, 2006; SERVA; ANDION, 2007; LÉVESQUE, 2007). Granovetter, considerado, por isso, o fundador da NSE, objetiva analisar até que ponto a ação econômica está imersa nas estruturas das relações sociais na moderna sociedade industrial. Desde então, as discussões sobre a NSE emergiram com vigor no meio acadêmico, principalmente por terem os pesquisadores voltado seu olhar aos fenômenos econômicos sob o viés sociológico a partir de novas perspectivas. Em razão da amplitude de foco que a NSE ganhou, Lévesque (2007) apresenta uma sintetização (Quadro 1) sobre as principais abordagens referentes à NSE desde sua origem, sendo esta inglesa ou francófona, e seus principais representantes e paradigmas. 
Quadro 1 - Abordagens da NSE

\begin{tabular}{|l|l|}
\hline \multicolumn{1}{|c|}{ Língua Francesa } & \multicolumn{1}{|c|}{ Língua Inglesa } \\
\hline $\begin{array}{l}\text { MAUSS: contra o utilitarismo; o paradigma da dádiva (Caillé } \\
\text { e Godbout). }\end{array}$ & $\begin{array}{l}\text { Nova Sociologia Econômica: redes e imersão social da } \\
\text { economia (Granovetter) }\end{array}$ \\
\hline $\begin{array}{l}\text { Economia social e solidária, economia plural (Laville e e } \\
\text { Roustang). }\end{array}$ & $\begin{array}{l}\text { Evolucionistas e neoschumpeterianos: sistemas sociais } \\
\text { de inovação (Nelson, Winter, Dosi, Freeman). }\end{array}$ \\
\hline $\begin{array}{l}\text { Regulacionistas: instituições e compromissos sociais, modelo } \\
\text { de desenvolvimento (Aglietta, Boyer e Lipietz). }\end{array}$ & $\begin{array}{l}\text { Neocorporativistas: governança e democracia social } \\
\text { (Schmitter e Streeck, Hollingsworth). }\end{array}$ \\
\hline $\begin{array}{l}\text { Economia da grandeza: mundos e cidades (Boltanski, } \\
\text { Chapiello, Thévenot). }\end{array}$ & $\begin{array}{l}\text { Novos institucionalistas: bifurcação e especialização } \\
\text { flexível (Piore Sabel, Hodgson). }\end{array}$ \\
\hline $\begin{array}{l}\text { Economia das convenções: mundo da produção e mercado } \\
\text { como organização (Favereau, Orléan, Salais). }\end{array}$ & $\begin{array}{l}\text { Socioeconômica: nova disciplina e dupla dimensão da } \\
\text { economia (Etzioni, Lawrence e Coughlin). }\end{array}$ \\
\hline
\end{tabular}

Fonte: LÉVESQUE, 2007, p. 51.

Dentre todas estas abordagens, este trabalho ancora-se na perspectiva das obras de Marcel Mauss ${ }^{4}$ (2003a, b, 2006), e mediante os trabalhos de Caillé (1998, 2002, 2011) e Godbout $(1998,1999,2005)$ - ambos autores que se propuseram a divulgar os estudos de Mauss. Além disso, também foram consideradas as pesquisas do movimento Mauss. ${ }^{5}$

O referido movimento foi criado durante o evento de 1981, na França, no qual os pesquisadores Thomas More, Gérald Berthoud e Alain Caillé ficaram surpresos com a quantidade de participantes que desconheciam as obras de Mauss, principalmente o conceito de "fato social total" por ele criado. A partir desse incômodo, Caillé (1998) decidiu criar este movimento e incitar a disseminação dos estudos de Mauss com o uso da Revista Mauss, existente até hoje.

Segundo Caillé (2011), o termo "antiutilitarismo" representa uma oposição ao movimento dominante, representado, neste caso, pelo utilitarismo. O movimento Mauss não aceita a conceituação de homo oeconomicus como a explicação hegemônica de toda ação humana. Contesta ainda o argumento de que todos os indivíduos seriam egoístas e que agiriam em razão de suas próprias vontades. Por isso, defende o terceiro paradigma: o da dádiva. Assim, o movimento antiutilitarista critica o economicismo nas ciências sociais e o racionalismo instrumental na filosofia moral e política. Prestando homenagem a Marcel Mauss, este movimento encoraja-nos a pensar no vínculo social em termos dos "dons" que unem os sujeitos humanos.

O paradigma da dádiva foi idealizado e sistematizado por Caillé com base nas obras de Mauss e das inúmeras contribuições da Revista du Mauss. Cabe destacar que, mais tarde, Caillé recebeu o apoio de Jacques Godbout, principalmente em sua obra "L'esprit du Don", de 1992. De acordo com Lévesque (2007), trata-se de uma das principais contribuições francesas à NSE, que busca interpretar a imersão social da economia no utilitarismo e a crítica a ele. Este paradigma tem por matriz fundamental a crítica ao utilitarismo a partir das relações sociais e da troca mercantil, algo que é considerado posterior à dádiva.

\footnotetext{
${ }^{4}$ Marcel Mauss era sobrinho de Émille Durkheim, tendo trabalhado ao lado do tio na coordenação da revista l'Année Sociologique, além de ter sido cátedra de "história das religiões dos povos não-civilizados" na École Pratique des Hautes Études de Paris, e suas principais obras são Ensaio sobre a dádiva (1925) e Manual de Etnografia (1947).

${ }^{5}$ Principalmente da La Revue du MAUSS - Disponível em: http://www.revuedumauss.com.fr/.
} 
Das contribuições de Caillé e Godbout, compreende-se que o utilitarismo representaria o primeiro paradigma dominante, que procura explicar o mercado, as estruturas sociais, os sistemas de produção e, sobretudo, a "circulação das coisas e dos serviços na sociedade a partir das noções de interesse, de racionalidade, de utilidade" (GODBOUT, 1999, p. 1). Sob este viés, os pesquisadores acreditam ser possível explicar os fenômenos sociais mediante cálculos racionais efetuados pelos indivíduos, reconhecendo o princípio ético que norteou a sua decisão em razão do custo benefício da ação. O segundo paradigma teria uma inclinação mais holística, com base em diversas visões, como o funcionalismo, o culturalismo, o institucionalismo e o estruturalismo. $O$ pesquisador tenta explicar o funcionamento das estruturas sociais e as ações individuais e coletivas que interferem no momento da decisão do indivíduo. Por fim, o terceiro paradigma (dom) representa uma terceira rede de circulação de coisas e serviços nunca percebida pelos paradigmas anteriores - a rede da sociabilidade (CAILLÉ, 2002). Agora, os "bens são meios postos ao serviço da criação e da consolidação de vínculos sociais e aquilo que importa em primeiro lugar não é tanto o valor de uso ou o valor de troca quanto aquilo a que poderia se chamar de valor de vínculo" (CAILLÉ, 1998, p. 9). Este paradigma, portanto, defende que é possível estudar a imersão social da economia, de forma antiutilitarista, a partir da tríplice obrigação de dar, receber e retribuir, porém sem desconsiderar os fundamentos do utilitarismo nem considerar os humanos altruístas. A dádiva revela como os objetos trocados transluzem os relacionamentos pessoais e o vínculo social cunhado entre os homens.

\section{REFLEXÕES SOBRE A TEORIA DA DÁDIVA}

A teoria da dádiva surgiu como um movimento contrário à lógica do mercado utilitarista, retratando haver outras formas de se entender as trocas presentes dentro da sociedade. A obra de Mauss é considerada um marco no desenvolvimento da sociologia durkheimiana. Para Caillé (1998), esse desenvolvimento refere-se ao avanço de Mauss sobre os estudos de Durkheim pela descoberta do simbolismo. "As palavras, as saudações, os presentes, solenemente trocados e recebidos, e obrigatoriamente retribuídos sob risco de guerra, o que são, senão símbolos?" (CAILLÉ, 1998, p. 9). Mauss obteve uma considerável progressão, se comparada à de seu tio, em razão do seu olhar sobre a Antropologia, do seu posicionamento crítico ante a filosofia e da adoção de uma etnografia para as sociedades não ocidentais.

Analisar as relações de troca dentro dos mercados foi objeto de diversos autores clássicos, que inspiram muitos pesquisadores a lançar novos olhares sobre as relações de troca de diferentes formas. Já no século 20, Godbout (2005) afirma que, com o avanço da tecnologia, as trocas e os relacionamentos estão cada vez mais digitais, impessoais e mecanizadas, decorrentes de aplicativos para smartphone, autoatendimentos e caixas eletrônicos, por exemplo. Este cenário "não elimina a necessidade de explicar as trocas de outros tipos, entre seres humanos, em que ocorre algo diferente e que permanecem fundamentais, até mesmo, em economia" (GODBOUT, 2005, p. 82).

Em Ensaio sobre a Dádiva: forma e razão da troca nas sociedades arcaicas, Mauss (2003b) analisa as dádivas trocadas e a obrigação de retribuí-las. É nesse momento que fica clara a sua preocupação central em não explanar um fenômeno social a partir de outro fenômeno, mas em explicá-lo a partir de diversos fenômenos e de sua importân- 
cia para determinada sociedade. A dádiva, portanto, pode ser interpretada como uma configuração em que ocorre a circulação de bens (materiais ou simbólicos) com o objetivo central de criar, recriar ou fortalecer os vínculos dentro da sociedade. Para Godbout (1999), a dádiva pode ser entendida como uma circulação de bens e serviços (fora do mercado), o que fortalece a (re)criação do laço social, pois ela existe para as pessoas com as quais se deseja relacionar, como acontece no Natal, a maior exemplificação desse fenômeno na atual sociedade.

Mauss (2003a) apresentou o sistema de prestações totais (Potlach) que contextualiza as dádivas trocadas e a obrigação de retribuí-las em uma comunidade da Polinésia. Em suas observações, destaca como ocorria a oferenda voluntária de presentes, livre e gratuita, porém, simultaneamente, interessada e obrigatória. Com base nessa evidência, conclui Mauss (2003a) que em nossa sociedade existe uma tríade concebida em "dar, receber e retribuir". Neste sentido, e mais recentemente, Vizeu (2009) afirma que um determinado sujeito pode buscar relacionamentos a partir de três maneiras: criar, recriar e manter o vínculo social. Segundo o autor, essas três formas de se relacionar podem ocorrer por intermédio da troca de bens, situação em que o valor financeiro não é considerado no momento da troca, pois o que vale é o símbolo da efetivação. Temos aí a obrigação desobrigada, presente no convívio das pessoas. "É assim que nos expomos não só a obrigar como a nos tornar obrigados” (GODBOUT, 1999, p. 21).

A dádiva não é gratuita e necessita de reciprocidade para ser efetivada. Caso contrário, sem reciprocidade o elo é rompido e não existe a dádiva. "Assim, ou a obrigação de retribuir é assumida, e então se estabelece um círculo de relações de pessoa a pessoa, dentro do qual os bens alimentam a ligação, ou é recusada através de uma contradádiva monetária imediata" (GODBOUT, 1999, p. 19). A obra de Mauss é complexa e atemporal. Por fim, é preciso relatar que foi a partir da contribuição do simbolismo e sua relação com a vida social que Mauss superou Durkheim. Mauss fez analogia da compreensão simbólica aos relacionamentos e acreditava que a oposição entre as coisas e as pessoas não fazia sentido. Assim, o fato social (durkheimiano) não pode ser apenas considerado coisa. Surge, então, a visão de Mauss sobre o "fato social total", em que é necessário tratar os fatos sociais não mais como simples coisas, mas de acordo com a lei do simbolismo - que condiciona o sistema de prestações e contraprestações entre os homens e a existência de dar, receber e retribuir.

\section{OS ESTUDOS TERRITORIAIS E A IMPORTÂNCIA DO TRABALHO DE CAMPO}

A retomada dos estudos territoriais objetiva fornecer subsídios para uma melhor compreensão sobre o desenvolvimento de uma dada localidade (ABRAMOVAY, 2010). A retomada proposta neste trabalho dá ênfase aos atores, ou seja, projeta luz sobre a experiência, a ação e a prática dos atores e suas consequências, pois os desafios territoriais cresceram acompanhando a difusão do capitalismo (RIVERO, 2001) e elevaram a vulnerabilidade dos cidadãos a uma gama de ameaças e perigos que envolvem questões sociais, ambientais e econômicas (SACHS, 2009). 
Quanto à conceitualização, Gumuchian et al. (2003) resgatam a obra de Frémont "A região, o espaço vivido", no qual o autor sinaliza para a necessidade de reconhecer os habitantes como sujeitos ativos e pensantes do seu próprio território. "O território é compreendido como um espaço social e real que se impregna de valores culturais refletindo, para cada um, o pertencimento a um grupo localizado" (p. 25).

Quer dizer, o território é muito mais do que o limite de um lugar; indica, afinal, a natureza simbólica e material, criada pelos atores e formada por diferentes configurações espaciais. O território é um campo de força representado por inúmeros atores que lutam por seus interesses e legitimidades (GUMUCHIAN, 2002). É no bojo do território que acontecem a dramatização, as cenas, o espaço da vida resultante da ação coletiva entre os atores - o que forma a territorialidade. A ação coletiva, para Cefaï (2013b), ocorre a partir do agenciamento de atores, objetos, falas, ritos e símbolos. Esta ação é orquestrada mediante rotinas e operações que cristalizam a vivência de um grupo mediante articulações que promovam divisões do trabalho, poder, saber, compartilhamento de objetos, dispositivos sociotécnicos e circuitos operacionais. Daí a importância do trabalho de campo para identificar e compreender as relações sociais e demais ações coletivas dos atores que produzem inúmeras consequências para o território. Ou, como argumentou Abramovay (2010),

O estudo dos territórios sob o ângulo das forças sociais que os compõem não só é um convite a análises empíricas bem fundamentadas sobre sua constituição - mais do que de recomendações de política - mas abre caminho para se compreender as mudanças que novas forças sociais podem imprimir à maneira como estão hoje organizados (p. 44).

Segundo Gumuchian et al. (2003), a ciência, historicamente, não valorizou a análise dos insumos do micro (preferencialmente) para, então, reter a construção e a análise das escalas meso e macro. A isto se deve a concepção atribuída ao ator nas ciências sociais, vaga, polissêmica e deturpada. O caráter microscópico, obtido no trabalho de campo, no entanto, apresenta-se como uma arte que permite ao pesquisador compreender o ator a partir da "realidade". Metodologicamente, os atores representam a possibilidade da entrada pelo micro dos indicativos da operação macro - global. O território é uma fração do global (do micro ao macro). As relações territoriais locais são, ao mesmo tempo, relações territoriais globais. Por isso, diferentes autores defendem a necessidade de se retomar os estudos etnográficos e trabalhos de campo para a compreensão dos atores, de suas práticas e experiências; entender como eles dão vida, movimento e simbologia ao território (SMELSER; SWEDBERG, 2005; CEFAÏ, 2013a).

A etnografia é uma particularidade da antropologia, a qual, conforme Laplantine (2004), independe da sociedade estudada, do objeto de análise ou das teorias balizadoras. O que importa é o projeto - o estudo do homem como um todo em todas as sociedades. Ela permite a compreensão da pluralidade das culturas, das relações humanas, da familiaridade e do compartilhamento das relações entre os homens. A etnografia 
já foi foco de estudo desde as clássicas contribuições de Franz Boas e Bronislaw Malinowski, até autores mais recentes, como Clifford, Laplantine e Cefaï. Ademais, a etnografia foi alvo de estudos do próprio Mauss. ${ }^{6}$

Desde estas clássicas contribuições, a etnografia ressignificou-se e incorporou outras metodologias e instrumentos de coleta de dados. Cefaï (2013a, b), por exemplo, indica o diário de campo como um dos principais instrumentos do etnógrafo, afirmando ser preciso articulá-lo com outros métodos, como a observação direta, ou participante, para citar alguns. Assim, o pesquisador estará em contato com os atores e (re)conhecerá as experiências, atividades primárias e situações cotidianas. Para Cefaï (2013a, b), é importante que o pesquisador saiba quem são os atores, o que eles fazem e por que eles o fazem; além de identificar os conflitos e as consequências dos discursos e das ações empregadas. Por tudo isso, é impossível falar em etnografia sem ter esse momento de observação, compreensão e descrição dos atores e seus territórios, num determinado espaço-tempo.

A inspiração para associar a etnografia aos estudos da NSE, representada aqui pela corrente francófona da dádiva, ocorreu por duas razões fundamentais. Primeiro, por Smelser e Swedberg (2005) afirmarem que, quanto à operacionalização das pesquisas, os fenômenos ainda são avaliados com supremacia na aplicação de modelos randomizados em forma matemática, sendo praticamente inexistente o trabalho etnográfico. Para os autores, há que se conduzir pesquisas com postura etnográfica, valendo-se do estranhamento necessário para a compreensão de um fenômeno, contrapondo as abordagens tradicionais das teorias econômicas. Segundo, pelo próprio Mauss (2006), que destaca a importância do trabalho etnográfico e defende que a sociedade não se explica por uma única característica, mas pela articulação de diferentes partes que formam o seu todo, o que exige do etnógrafo toda atenção aos fatos e também aos detalhes.

Para Mauss (2006), essa totalidade é representada pelo fato social total que revela como diferentes esferas de uma sociedade (econômicas, culturais, políticas, religiosas e outras) permeiam seu imaginário e influenciam os indivíduos em suas ações. Compreende-se, a partir disso, que a etnografia é uma estratégia de pesquisa que possibilita identificar como ocorrem os processos relacionais, as representações, as conexões, as influências e a realidade dos homens e, neste caso, como isto impacta na formação e no desenvolvimento do território.

Dessa forma, uma visão antiutilitarista proporciona ao estudo territorial a possibilidade de caminhar por um eixo de desenvolvimento que não pode ser confundido com crescimento econômico, o que também é condição necessária, mas não suficiente (SACHS, 2009). "O desenvolvimento econômico e social buscado há mais de meio século se mostra cada vez mais fugido" (RIVERO, 2001, p. 183). Ademais, no caso do estudo das sociabilidades nos mercados, essa visão permitirá evidenciar aspectos históricos localizados geograficamente, composto por entidades vivas e encarnadas, que dão vida e forma ao território. Ou, como expôs Abramovay (2004):

\footnotetext{
${ }^{6}$ Por questões de foco e de síntese, nessa argumentação não será feita uma revisão e amplo debate sobre as diferentes correntes etnográficas; nem objetivamos narrar como fazer a etnografia, mas, sim, chamar a atenção sobre a necessidade de se adotar mais esta perspectiva aos estudos territoriais para compreender o homem e o território. Para um maior aprofundamento ver CEFAï, $(2013 a, b)$.
} 
Nesse caso, sua compreensão [o mercado no território] faz apelo à subjetividade dos agentes econômicos, à diversidade e à história de suas formas de coordenação, às representações mentais a partir das quais se relacionam uns com os outros, à sua capacidade de obter e inspirar confiança, de negociar, fazer cumprir contratos, estabelecer e realizar direitos (p. 36)

A análise das questões de desenvolvimento e reações populares não pode ser desarticulada do estudo das dinâmicas locais e dos processos endógenos de mudança (OLIVIER DE SARDAN, 1995). Por esta razão, o presente estudo mostra que o desenvolvimento depende de diversos fatores culturais e não pode se limitar exclusivamente aos aspectos econômicos, ignorando as relações complexas da sociedade humana. Assim, uma ênfase às ações e relações dos atores, sob a ótica da NSE, especificamente da Dádiva, permitirá desvelar que há muito mais práticas presentes nos relacionamentos que uma simples ordem econômica direta. Há a criação de identidade e um fenômeno cultural ou, como exposto por Gumuchian et al. (2003), o lugar passa a ter um nome e essa designação não é indiferente à propriedade e à identidade. Nesse lugar, o ator executa sua prática, trabalho, lazer, religião, hierarquia, poder - organiza-se em rede, o que fortalece as relações afetivas e/ou de proximidade. Fica assim explicado por que a transformação socioeconômica acaba sendo construída por tantos outros fatores que entram na composição da tessitura social do território.

\section{PROCEDIMENTOS METODOLÓGICOS}

Esta pesquisa configura-se como uma abordagem qualitativa, pela finalidade exploratória e descritiva. A estratégia de investigação utilizada foi a da postura etnográfica, incluindo observação participante, pesquisa bibliográfica, análise documental e entrevistas.

A pesquisa bibliográfica foi parte fundamental deste estudo, pois permitiu identificar as pesquisas já realizadas e as teorias existentes sobre o fenômeno em questão. $O$ resultado deste esforço culminou com as reflexões e a literatura apresentada até aqui.

Conforme discutem Denzin e Lincoln (2000), Flick (2004) e Hoppen, Hoppen e Hayashi (2013), além das entrevistas (processo de fala e escuta) a observação é outra habilidade metodológica aplicada nas pesquisas qualitativas. É uma combinação simultânea de análise de documentos, entrevistas de respondentes e de informantes, participação e observações diretas e introspecção (DENZIN; LINCOLN, 2000). Ela possui algumas fases, como a seleção do ambiente, a definição do que deverá ser observado e o período da observação (FLICK, 2004).

A observação participante é uma forma de etnografia que vem sendo muito aplicada na Administração para entender o processo organizacional, a formação da sociedade e a gestão pública (HOPPEN; HOPPEN; HAYASHI, 2013). "Participação" no sentido exposto por Cefaï (2013a, p. 115), ou seja, "participar de mundos de significado sendo feitos; entrar no campo diferentes vezes para aprender sobre formas de experiência pública, além de aprender a dominar categorização e argumentação, os modos de ver e dizer das atividades de cooperação e comunicação" - tantas em um mundo comum. A postura etnográfica, segundo Cefaï (2013a), aconteceu em três etapas: registro, análise e apresentação de resultados. 
A fase do registro aconteceu em dois momentos. Primeiro a realização de uma trajetória da feira livre (parte 1 dos resultados) em pesquisas realizadas e nos jornais locais. Num segundo momento, ocorreu o trabalho de campo junto aos feirantes e consumidores nas sete feiras livres de Corumbá durante dez meses (2017-2018), momento em que também foram realizadas a entrevista semiestruturada (78 no total) e as conversas informais. Isso foi concretizado com os seguintes recursos: diário de campo, gravador e câmera fotográfica, estes dois últimos no aparelho celular.

O diário de campo foi o recurso mais utilizado. Nele, as passagens foram escritas em duas colunas: na coluna 1 com informações exatas - relatadas pelos próprios atores; na coluna 2 com a percepção do entrevistador sobre um dado evento. No trabalho etnográfico, a reflexividade é realizada pelo ir e vir constante aos universos do eu (pesquisador) e do outro (pesquisado) (CEFAÏ, 2013b). Nesse encontro, é preciso manter certo distanciamento e criar uma relação de cumplicidade e alteridade.

$\mathrm{O}$ cuidado na fase do registro favoreceu as duas etapas seguintes. Na análise, todo o material foi transcrito e considerado para que se chegasse às categorias analíticas que ajudaram na redação (fase do resultado) do texto. Tais categorias surgiram dos próprios atores, seres reflexivos que sabem o que fazem e "o que temos que aprender deles é não apenas o que eles fazem, mas como e por que eles o fazem" (LATOUR, 2012, p. 19). Chegamos, assim, às seguintes categorias: história da feira, o que é a feira e pontos de relacionamentos e trocas.

\section{RESULTADOS}

\section{Parte 1 - Para entender o Território e as Feiras na Fronteira Brasil-Bolívia}

A retomada dos estudos territoriais, como aqui proposto, visa a compreender como ocorrem as relações de troca e a presença do simbolismo na zona fronteiriça Brasil-Bolívia, especificamente nas feiras livres do município de Corumbá (Brasil), localizada na divisa destes dois países. Esta fronteira foi a escolhida pois, como será demonstrado a seguir, representa uma fronteira vivida, marcada por mobilidades humanas, econômicas e simbólicas (BENEDETTI, 2018).

Falar de feira livre é falar de riqueza cultural, social e econômica. Trata-se de uma estrutura social consolidada desde a Idade Média, quando os cidadãos começaram a se organizar em torno de bancas para vender, dentre outros artefatos, o excesso de produção. No momento da comercialização ocorria muita troca simbólica e cultural e as feiras passaram a ser vistas como patrimônio cultural e ponto turístico em diversas partes do mundo, como as feiras de Marrakech e Tanney, no Marrocos, ou a feira de São Cristóvão, no Rio de Janeiro.

Em Corumbá, as feiras surgiram em 3 de maio de 1959 (SANTO et al., 2018). Desde o início dos anos 90, a presença do feirante boliviano é notória nessas feiras, o que a caracteriza como um verdadeiro ponto de encontro da população fronteiriça, que adquire seus produtos e ainda experimenta um caudaloso sabor cultural em sete feiras espalhadas pela cidade (SANTO et al., 2018). Dessa forma, é possível afirmar que a feira 
livre é uma atividade histórica dentro de Corumbá/MS, com mais de 50 anos de existência e que diariamente faz parte do cotidiano da população local. A Figura 1 detalha um pouco esse espaço.

Figura 1 - A feira livre em Corumbá, em mosaico
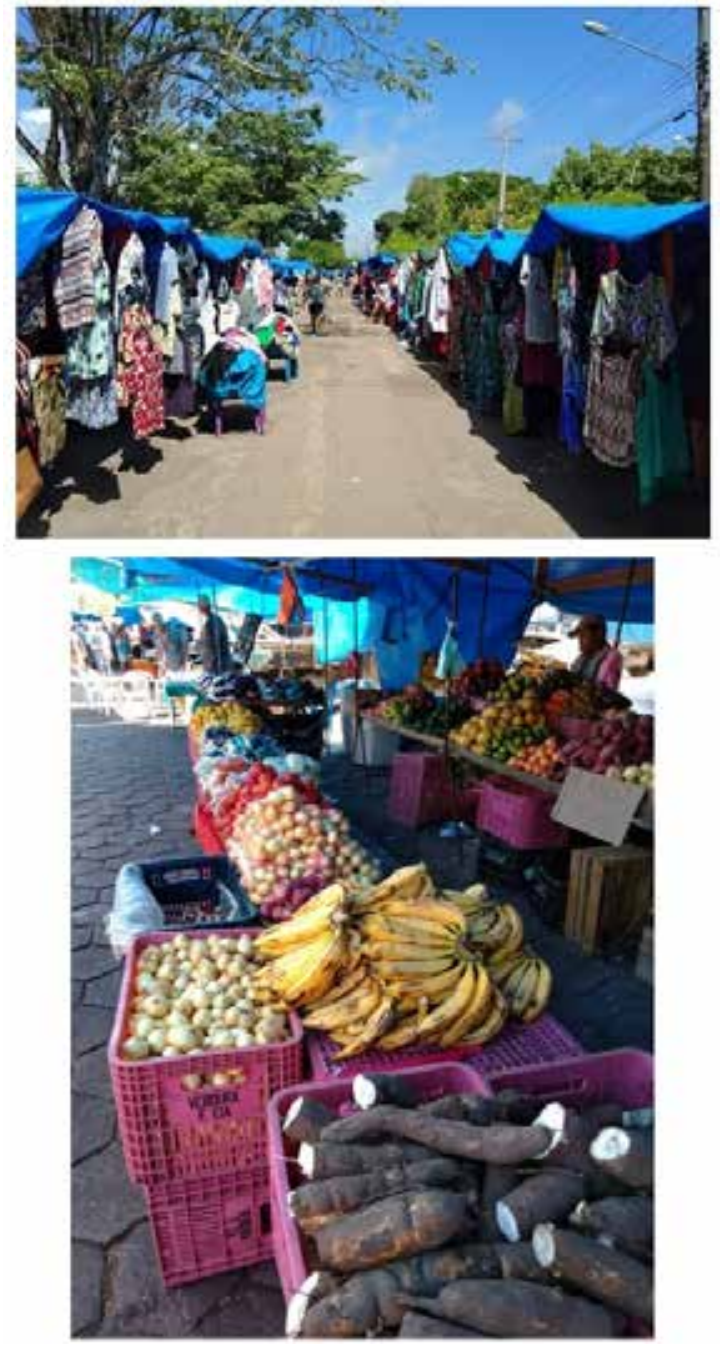
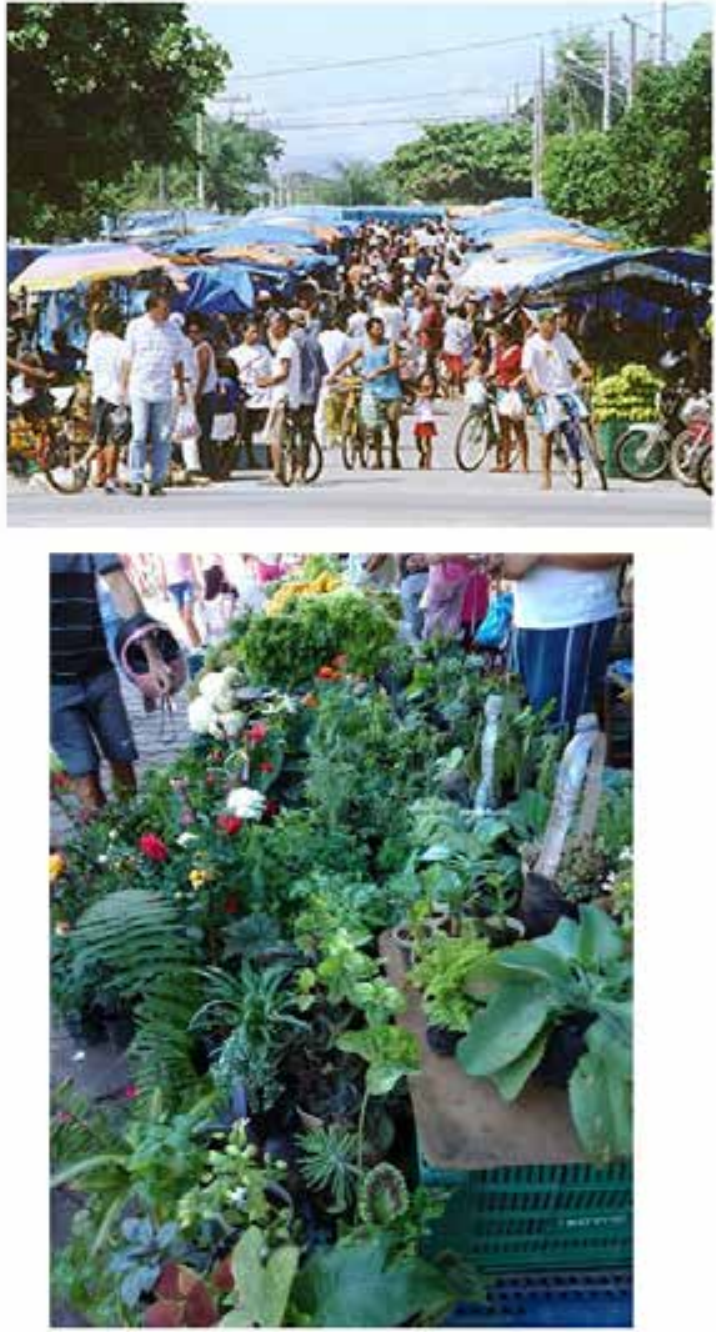

Fonte: Os autores.

Apesar, no entanto, de uma existência superior a meio século, a participação dos feirantes bolivianos nas feiras livres de Corumbá com frequência é discutida pelo poder público local, principalmente em razão da pressão dos comerciantes brasileiros. A última discussão ocorreu entre os anos de 2013 e 2015, quando foi fechado um centro comercial que abrigava feirantes brasileiros e bolivianos conhecido como Feira Bras-Bol, uma espécie de camelódromo na cidade. Esse fechamento fez eclodir uma grande instabilidade na região, pois passou-se a acreditar que os feirantes bolivianos estariam proibidos de trabalhar nas feiras livres. O fechamento das feiras por parte do governo local é algo histórico nesta fronteira, justificado pelo problema de "gestão" desse tipo de atividade. Os fechamentos, no entanto, mostraram-se ineficientes, posto que os atores voltaram a se reagrupar e organizar a abertura de novas feiras. 
Essa instabilidade ocorreu em razão de dois problemas fundamentais. Primeiro, a falta de gestão por parte do poder público municipal, dado que organizar o funcionamento das feiras livres é uma atividade instituída na Constituição Federal de 1988, sendo dever do município regulá-las. Segundo, o fato de essas feiras apresentarem características particulares que sinalizam um desvirtuamento de sua lógica de criação. No espaço em que, originalmente, era para se vender o excedente da produção agrícola, também são encontrados produtos falsificados, como CDs/DVDs, roupas, plantas, brinquedos e outros artefatos (ver Figura 1). Algumas vezes são comercializadas carnes bovinas e suínas, além de leite in natura que, de alguma forma, escapam ao controle da fiscalização. Alimentos caseiros são frequentemente vendidos, caracterizando a feira como uma verdadeira quermesse. Ou seja, este território é marcado pelo comércio legal e/ou ilegal, algo frequente e que explica, em parte, as mobilidades na fronteira em torno das feiras livres.

\section{Parte 2 - Percepção da Teoria da Dádiva na Fronteira: Símbolos, Trocas e Solidariedade Conspiram em um Mesmo Sentido}

Ao caminhar pelas feiras de Corumbá percebem-se múltiplas sensações de sons, cheiros, cores e sabores. Nesse espaço a fronteira é um local que permite variados convívios de grupos de imigrantes, impulsionados por distintos motivos, em momentos históricos particulares e com interesses também particulares. A fronteira é palco de união e crescimento mútuo. Durante as visitas às feiras foram encontrados brasileiros, bolivianos, argentinos, paraguaios, colombianos, peruanos, chineses, sírios, haitianos e palestinos. Esse é um território marcado por um hibridismo cultural no qual as trocas são materiais, mas, principalmente, culturais, pois o dar e o receber se estabelecem também nas socializações e manifestações culturais.

Nessas feiras percebe-se a predominância de feirantes bolivianos, pois a influência dessa população está na comercialização da feira, na cultura, na culinária e, visivelmente, até nas vestimentas. As feiras também possuem forte influência paraguaia, pois a cidade comunica-se via fluvial com o Paraguai.

A comercialização ocorre em sete feiras nos sete dias da semana. A feira de domingo é a maior delas e a mais tradicional. As feiras começam a ser organizadas às 5 horas da manhã e se estendem até as 14 horas. Por vezes são encontrados feirantes que cedem espaço em suas bancas a oriundos da produção da agricultura familiar em um dos assentamentos da região para venderem seus produtos. Quando perguntado por que o feirante cede/recebe o espaço, um dos entrevistados relatou: "Ele é meu compadre e como ele não consegue uma autorização para começar a vender aqui na feira eu cedo esse 'espacinho' para ele vender seus produtos; afinal, ele sempre me ajuda na colheita e aqui nas vendas".

Essa fala repetiu-se por algumas bancas e esse relacionamento será aqui chamado como "relações de compadre". Nessa relação, o feirante cadastrado junto a prefeitura (autorizado a comercializar na feira) empresta um pequeno espaço em sua banca para o compadre (não cadastrado) vender. Observamos aqui a presença da dádiva e suas contraprestações, porque as justificativas para tal ato são sempre de gratidão e de dívida recíproca. Como afirmado outrora, a dádiva ainda existe para as pessoas com as quais 
se deseja relacionar e (re)cria o vínculo social entre os sujeitos. Nesse caso, observa-se que, por mais que seja um laço construído para a efetivação de um comércio (ceder o espaço na banca para o compadre vender), não se constata a presença de um valor financeiro, e a ação (ceder espaço) gera uma obrigação desobrigada, o que estimula a convivência entre as pessoas.

Outros exemplos da "relação de compadre" foram observados entre brasileiros e bolivianos. A grande maioria dos feirantes não leva seus produtos para a Bolívia ao final da feira. "Para não levar todos os meus produtos para Puerto Quijarro [Bolívia], eu acabo guardando na casa dos meus amigos aqui em Corumbá", relatou um feirante boliviano. Na sequência ele informou como isso ocorre. "É como se fosse uma troca. Todo mundo aqui ajuda todo mundo. Para esse meu compadre, que guarda meus produtos aqui em Corumbá, eu trago algumas mandiocas e hortaliças da Bolívia para que ele possa ter mais produtos para vender em sua banca". Semelhante a esse caso, Godbout (1998, p. 9) explica que se entende por "dádiva tudo o que circula na sociedade e que não está ligado nem ao mercado, nem ao Estado, nem à violência física. De modo mais positivo, é o que circula em prol do ou em nome do laço social".

Sobre a construção de laços sociais dos feirantes brasileiros e bolivianos, destaca-se que os agricultores feirantes que participam das feiras não veem a presença de comerciantes de produtos não agrícolas como um problema. Ao contrário, percebem neles uma razão a mais para atrair pessoas até a feira e ampliar as possibilidades de exposição de seus produtos. "Se fosse só para comprar frutas, legumes, vocês não viriam até a feira. Comprariam tudo no supermercado que, às vezes, é até mais barato. As pessoas que vêm aqui também querem ver roupas, lanchar, passear, e daí já leva nossa verdura", relatou o produtor rural/feirante brasileiro. Vemos aí que as feiras se configuram como uma verdadeira rede de relações ou laços sociais. Justifica-se esta formação de laços sociais com Lazzarini (2011, p. 4), quando, segundo o autor, os "laços podem denotar relações próximas, íntimas, duradouras. Aqui, entretanto, o significado é mais no sentido de relações sociais valiosas: um contato pessoal que é estabelecido para obter algum benefício particular ou, ainda, um gesto de apoio visando algo em troca no futuro".

Essas trocas mercantis evidenciam como ocorrem as relações sociais entre os atores na feira livre. Além de uma visão utilitarista, vemos, a partir da dádiva, uma rede de sociabilidade que consolida os vínculos sociais. O que são todas as trocas relatadas senão símbolos? O que são, senão dádivas?

Outra forma de construção de dádivas advém das trocas culturais (Figura 2); afinal, a feira tem um papel sociocultural imenso. Trata-se de um ponto de encontro de brasileiros e bolivianos que compartilham a língua, a religiosidade, a alimentação, as famílias e tradições, dentre outros. A imagem demonstra a troca cultura em torno de plantas medicinais, quando há um compartilhamento cultural e de conhecimento de cada povo. A seguir, destacam-se três compartilhamentos e prestações totais identificados no trabalho de campo. 


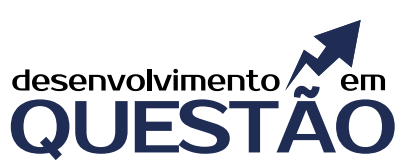

\section{Figura 2 - As trocas culturais}

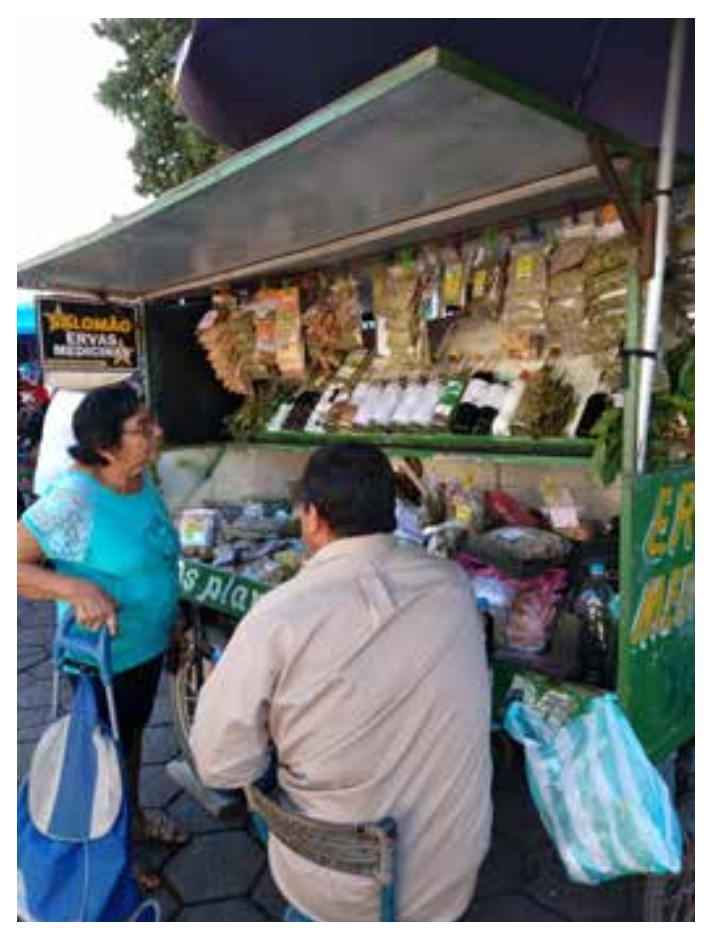

Fonte: Os autores.

Inicialmente temos o compartilhamento do portunhol, mistura de palavras da língua portuguesa e espanhola, em que, diariamente, a comunicação é intensa e a língua não é uma barreira; ao contrário, flui com naturalidade e há reciprocidade em aprender argumentos e demais expressões que caracterizam os dois países. Um feirante brasileiro narrou: "Quando falamos o portunhol é uma forma de abraçar o nosso irmão, seja brasileiro ou boliviano. Ele [feirante boliviano] é bem-vindo aqui e é na nossa fala, e até na música, que o nosso espaço [a feira] vai sendo formado". O segundo destaque vai para o compartilhamento da religião, fator em que brasileiros e bolivianos se unem para celebrar as festividades de Nossa Senhora de Aparecida (padroeira do Brasil), a Virgem de Urkupiña e Copacabana (uma santa e a padroeira da Bolívia respectivamente) (Figura 3). As bolivianas entrevistadas relatam que participam do desfile comemorativo das santas e que os brasileiros fazem questão de fazer parte da festa das "Virgens" bolivianas. Há alguns anos, essas feirantes também começaram a distribuir saquinhos de doces na festa de Cosme e Damião (festa fortemente cultuada em Corumbá), ou seja, foi evidenciada uma troca religiosa quando as festas são realizadas em casas de brasileiros e bolivianos, ano a ano, a partir de contraprestações em torno da fé e que se encontram nas feiras - a arena onde se efetivam todas as ações dessa gente - comerciais, relacionais, políticas, culturais e outras.

Nunca se constatam simples troca de bens. O que eles trocam não são exclusivamente bens e riquezas, coisas úteis economicamente. São, antes de tudo, amabilidades, dos quais o mercado é apenas um dos momentos, e nos quais a circulação de riquezas não é senão um dos termos de um contrato bem mais geral e bem mais permanente (MAUSS, 2003, p. 190-191). 
Figura 3 - Celebração na festa de Urkupiña ${ }^{7}$

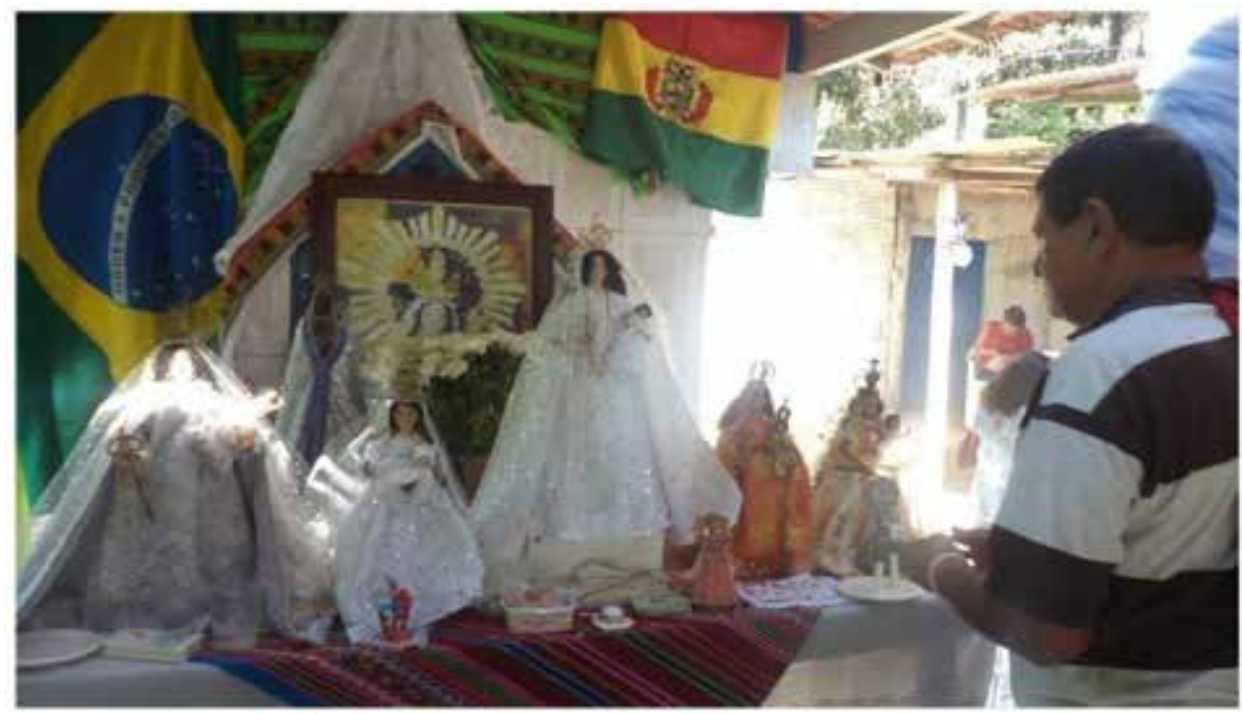

Fonte: Os autores.

O terceiro compartilhamento refere-se à comida e às festas cívicas, ocasião em que se encontraram brasileiros comercializando as tradicionais sopas que aos bolivianos tanto apetecem. A troca e a retribuição, cada qual com um prato típico de sua região, ocorrem diariamente nas feiras e com intensidade em festas cívicas, que também são compartilhadas. "Todos os anos nós, brasileiros e bolivianos, desfilamos no aniversário de Corumbá". "Fazemos questão de desfilar um na festa do outro" [referindo-se à festa de independência de cada país] - relato de um feirante boliviano e, outro, de brasileiro. Aqui, esse compartilhamento cívico e alimentar, que se inicia nas feiras, pode ser considerado magia, pois se refere a um compartilhamento que envolve todo um grupo, e não apenas uma parte. Mauss (2003b) afirma que os atos, quando se reptem, tornam-se mágicos - aceitos e incorporados pela sociedade, transformando-se em símbolo. "Há muito a magia é objeto de especulações. Mas as dos antigos filósofos, alquimistas e teólogos, sendo puramente práticas, [...] não devem ter lugar na história dos trabalhos científicos que o nosso tema ensejou" (MAUSS, 2003b, p. 49).

A partir do fato social total desenvolvido por Mauss, observamos outros aspectos nos casos narrados que vão além do viés econômico, tais como o culto e a língua, que geram símbolos que possibilitam compreender o processo de socialização desse território. O fato social total possibilitou notar uma verdadeira quebra dos padrões dominantes e uma exemplificação de como o fato social pode caracterizar a realidade. A magia aqui é compreendida como um rito, uma referência para toda a sociedade. A dádiva, nesse caso, acaba por fortalecer o laço social presente entre brasileiros e bolivianos e, subsequentemente, fortalecendo a estrutura social criada por ambos os lados - as feiras livres. Em razão das dádivas trocadas e da obrigação de retribuí-las, a dimensão

A imagem mostra a Virgem de Urkupiña (maior ao centro) acompanhada de diversas imagens de Virgem Maria. Ao fundo, ao lado do quadro, temos a imagem de Nossa Senhora de Aparecida e as bandeiras do Brasil e da Bolívia. Sob a mesa estão depositadas as alasitas, que são miniaturas de casas, carros, dinheiro e outros objetos, que são ofertados pelo fiel à Virgem de Urkupiña, que espera ser agraciado pela santa a conseguir aquele determinado bem. 
simbólica acaba ultrapassando a dimensão utilitária, o que justifica a presença-permanência de bolivianos na feira da cidade. Logo, a discussão sobre a permanência, ou não, desses feirantes, não deve ser feita unicamente pelo viés utilitarista do mercado. Aqui, o paradigma do "dom" abre inúmeras possibilidades de pesquisa e caracterização de um povo, imbricado na fronteira oeste do Brasil. A fronteira é, pois, um espaço de amalgamação sociocultural. Para compreender a fronteira, é preciso pensá-la sob inúmeras frentes culturais, econômicas, territoriais, legais, sociais, simbólicas, políticas e, agora, pela da dádiva.

\section{CONSIDERAÇÕES FINAIS}

O presente estudo buscou apresentar uma construção teórico-empírica fundamentada nas abordagens da Nova Sociologia Econômica, especificamente no paradigma do "dom", concebida a partir dos estudos de Marcel Mauss e fortalecida, sobretudo, por Caillé e Godbout. Mediante essa construção, a análise empírica demonstrou como ocorrem as relações de troca e a presença do simbolismo nas feiras livres da fronteira Brasil-Bolívia.

A análise do caso apresentado permitiu evidenciar que o paradigma da dádiva pode ser interpretado como uma estratégia global de pesquisa, pois é nas características locais (micro) que se encontrarão o mundo global (macro), as emoções, o cotidiano, os discursos e as ações a serem descobertas pelo investigador. Isso porque os símbolos, as trocas e a solidariedade conspiram num mesmo sentido. Afinal, ao compreender 0 social como um simbolismo, Mauss retrata os meios que caracterizam a realidade de um sujeito, orquestrado por uma variedade de fenômenos econômicos, jurídicos, religiosos e artísticos (reagregados pela NSE), que pactuam sobre a racionalidade do indivíduo e propiciam o sistema de prestações totais - dádivas trocadas e a obrigação de retribuí-las, fomentando a obrigação desobrigada e consolidando a formação dos mercados e das estruturas sociais.

Apesar de a sociedade atual viver em um mundo sem fronteiras para o capital, os produtos e as pessoas deslocam-se diariamente em verdadeiros rituais de passagens, impulsionadas por inúmeras motivações pessoais. Isto justifica a importância de se estudar os mercados sob o ângulo econômico, sociológico, histórico, ou seja, como construções sociais, pois, no caso de uma feira livre localizada no epicentro de dois territórios nacionais, observou-se, como disse Mauss, que o mercado é apenas um dos momentos, e, em razão disso, a feira é palco de socialização dos atores. Melhor dizendo, a fronteira une mais do que separa as populações. Essa afirmativa é confirmada por meio das trocas simbólicas narradas, pois foram observadas diversas prestações totais. Esta reciprocidade cristaliza a presença do paradigma da dádiva nas feiras e proporciona aos estudos territoriais a capacidade de visualizar muito mais do que trocas: a circulação de bens materiais e simbólicos e o quanto isso fortalece os vínculos entre os atores e a formação do território.

Por isso, a principal contribuição da teoria da dádiva para o desenvolvimento de novos estudos territoriais é a tradução que ela faz das ações econômicas sob as variáveis sociológicas, dando ênfase aos laços, às redes e às socializações que envolvem as dinâmicas territoriais de desenvolvimento. As representações do território mostram como ocorre a apropriação e a transformação do espaço. A teoria da dádiva auxilia nos 
estudos e na organização territorial por proporcionar olhares inovadores, valorização da cultura, identidade e apropriação do espaço, reconhecendo como se dão as transformações materiais e simbólicas - fatores estes que devem ser levados em consideração, assim como todos os seus efeitos quando da elaboração de programas, políticas públicas e outros dispositivos que visam a ordenar o território. Ao enxergar muito além da dimensão utilitarista, a teoria da dádiva contribui com "os bastidores das relações comerciais", em que as trocas e a presença do simbolismo ocorrem e incidem na dinâmica do território, caracterizado, neste caso empírico, pelo funcionamento das feiras que, de outra forma, seriam difíceis e até inexistentes em razão dos distintos povos e das jurisdições internacionais.

Foi possível identificar relações de troca nesse território, e que elas ocorrem a partir de um viés antiutilitarista, não descartando, por isso, o viés economicista. As trocas realizadas unem os povos, e a presença do simbolismo acaba por particularizar uma localidade. Por isso, é necessário empreender mais esforços para que se perceba o desenvolvimento, por meio da articulação de seus vários adjetivos (econômico, social, ambiental, cultural, sustentável, outros), sob uma matriz de "mudança social". A apreensão combinada desses elementos permitirá interpretar o desenvolvimento a partir da realidade das populações, ao contrário do seu significado usualmente empregado (enquanto crescimento econômico). "O desenvolvimento não é um ideal nem uma catástrofe; é principalmente um objeto de estudo" (OLIVIER DE SARDAN, 1995, p. 45).

Tudo isso justifica a importância do trabalho de campo, das contribuições da etnografia e da análise empírica. Os pesquisadores contribuem com o desenvolvimento de enfoques teórico-analíticos próprios que motivam uma nova forma de se repensar os estudos territoriais, resgatando o clássico trabalho de se acompanhar as sociedades. Não se trata de encaixar o fenômeno em modelos explicativos, em questionários pré-fabricados. É necessário, como salientou Mauss (2006), o ponto de vista do nativo e não apresentar uma visão reducionista, empirista ou empobrecida da realidade.

\section{REFERÊNCIAS}

ABRAMOVAY, R. Entre Deus e o diabo: mercados e interação humana nas ciências sociais. Tempo Social Revista de Sociologia da USP, v. 16, n. 2, p. 35-64, 2004.

ABRAMOVAY, R. Para uma teoria dos estudos territoriais. In: VIEIRA, P. F. (org.). Desenvolvimento territorial sustentável no Brasil: subsídios para uma política de fomento. Florianópolis: Secco, 2010. p. 27-47.

BENEDETTI, A. Claves para pensar las fronteras desde una perspectiva geográfica. Geousp - Espaço e Tempo, v. 22, n. 2, p. 309-328, 2018.

CAILLÉ, A. Nem holismo nem individualismo metodológico: Marcel Mauss e o paradigma da dádiva. Revista Brasileira de Ciências Sociais, v. 13, n. 38, p. 5-37, 1998.

CAILLÉ, A. O princípio de razão, o utilitarismo e o antiutilitarismo. Sociedade e Estado, v. 16, n. 2, p. 1-31, 2001.

CAILLÉ, A. Antropologia do dom: o terceiro paradigma. Petrópolis: Vozes, 2002.

CAILLÉ, A. 10 questões para Alain Caillé: entrevista concedida à Valéry Rasplus. Nouvel Obs Blogs. Tradução Maíra Albuquerque, 2011.

CEFAÏ, D. ¿Qué es la etnografía? Debates contemporáneos. Arraigamientos, operaciones y experiencias del trabajo de campo. Persona y Sociedad, v. 27, n. 1, p. 101-119, 2013a.

CEFAÏ, D. ¿Qué es la etnografía? Inscripciones, extensiones y recepciones del trabajo de campo. Persona y Sociedad, v. 27, n. 3, p. 11-32, 2013b.

DENZIN, N. K.; LINCOLN, Y. (org.). Handbook of Qualitative Research. 2. ed. Califórnia: Thousand Oaks, 2000. 
FLICK, U. Observação, etnografia e métodos para dados visuais. In: FLICK, U. Uma introdução à pesquisa qualitativa. 2. ed. Porto Alegre: Artmed, 2004. p. 147-170.

GODBOUT, J. Introdução à dádiva. Revista Brasileira de Ciências Sociais, v. 13, n. 38, p. 1-14, 1998.

GODBOUT, J. O espírito da dádiva. Rio de Janeiro: Editora FGV, 1999.

GODBOUT, J. Homo donator versus homo oeconomicus. Finance \& Bien Commun, v. 22, n. 2, p. 38-46, 2005.

GRANOVETTER, M. Economic Action and Social Structure: the problem of embeddedness. The American Journal of Sociology, v. 91, n. 3, p. 481-510, 1985.

GUMUCHIAN, H. Entre forme et sens: le territoire comme objet géographique. Les entretiens du Pradel. 2ème édition. Paris: Academie de l'Agriculture de France, 2002.

GUMUCHIAN H. et al. Les Acteurs, ces Oubliés du Territoire. Paris: Anthropos, 2003.

HOPPEN, N.; HOPPEN, N.; HAYASHI, P. Observação participante em estudos de administração da informação no Brasil. Revista de Administração de Empresas, v. 53, n. 6, p. 604-616, 2013.

LAPLANTINE, F. A descrição etnográfica. São Paulo: Terceira Margem, 2004.

LATOUR, B. Reagregando o social: uma introdução a teoria ator-rede. São Paulo: Edusc, 2012.

LAZZARINI, S. G. Capitalismo de laços: os donos do Brasil e suas conexões. Rio de Janeiro: Elsevier, 2011.

LÉVESQUE, B. Contribuição da nova sociologia econômica para repensar a economia no sentido do desenvolvimento sustentável. Revista de Administração de Empresas, v. 46, n. 2, p. 49-60, 2007.

LÉVESQUE, B. Comentários: as bases teóricas e metodológicas do enfoque de desenvolvimento territorial sustentável: convergências e aportes específicos. In: VIEIRA, P. F. (org.). Desenvolvimento territorial sustentável no Brasil: subsídios para uma política de fomento. Florianópolis: Secco, 2010. p. 77-88.

MAUSS, M. Esboço de uma teoria geral da magia. In: MAUSS, M. Sociologia e antropologia. São Paulo: CosacNaify, 2003a. p. 47-178.

MAUSS, M. Ensaio sobre a dádiva: forma e razão da troca nas sociedades arcaicas. In: MAUSS, M. Sociologia e antropologia. São Paulo: CosacNaify, 2003b. p. 183-294.

MAUSS, M. Manual de etnografia. Buenos Aires: Fondo de Cultura Económica, 2006.

OLIVIER DE SARDAN, J-P. Anthropologie et Développement: essai en socio-anthropologie du chagement social. Paris: Karthala, 1995.

POLANYI, K. A grande transformação: as origens da nossa época. Rio de Janeiro: Campus, 1980.

RIVERO, O. O mito do desenvolvimento: os países inviáveis do século XXI. Rio de Janeiro: Vozes, 2001.

SACHS, I. Caminhos para o desenvolvimento sustentável. Rio de Janeiro: Garamond, 2009.

SANTO, A. L. O uso de fotografias e vídeos em pesquisa qualitativa: em busca de um novo olhar sobre os territórios fronteiriços. Revista ADM.MADE, v. 22, n. 2, p. 3-34, 2018.

SANTO, A. L. et al. Tramas territoriais na comercialização de produtos agrícolas em territórios fronteiriços. Mundo Agrário, v. 19, n. 42, 2018.

SERVA, M.; ANDION, C. Teoria das organizações e a nova sociologia econômica: um diálogo interdisciplinar. Revista de Administração de Empresas, v. 46, n. 2, p. 10-21, 2007.

SMELSER, N. The Sociology of Economic Life. New Jersey: Prentice-Hall, 1976.

SMELSER, N.; SWEDBERG, R. Introducing Economic Sociology. In: SMELSER, N.; SWEDBERG, R. (ed.). The Handbook of Sociology Economic. New York: Princeton University Press, 2005. p. 16-38.

STEINER, P. A sociologia econômica. São Paulo: Atlas, 2006.

SWEDBERG, R. Markets as Social Structures. In: SMELSER, N.; SWEDBERG, R. (ed.). The Handbook of Economic Sociology. New York: Princeton University Press, 2005. p. 233-253.

VIZEU, F. D. Contribuições da Sociologia da dádiva aos estudos sobre organizações substantivas. Organização e Sociedade, v. 16, n. 50, p. 409-427, 2009. 